\title{
Current Status of Distress Screening in Designated Cancer Hospitals: A Cross- Sectional Nationwide Survey in Japan
}

\author{
Toru Okuyama, MD, $\mathrm{PhD}^{\mathrm{a}, \mathrm{b}}$; Yoshiyuki Kizawa, MD, $\mathrm{PhD}^{\mathrm{c}}$; Tatsuya Morita, $\mathrm{MD}, \mathrm{PhD}^{\mathrm{d}}$; \\ Hiroya Kinoshita, MD, PhD ${ }^{\mathrm{e}}$; Megumi Uchida, MD, PhD ${ }^{\mathrm{a}, \mathrm{b}}$; Asami Shimada, MD, PhD; \\ Akemi Shirado Naito, MD'; and Tatsuo Akechi, MD, PhD ${ }^{\mathrm{a}, \mathrm{b}}$
}

\begin{abstract}
Background: The purpose of this study was to investigate the current status of distress screening implementation in Japanese designated cancer hospitals. Subjects and Methods: This was a cross-sectional observational study. Palliative care team representatives in all designated cancer hospitals in Japan completed an ad hoc questionnaire. Demographic data in 2014 were obtained from the Ministry of Health, Labour and Welfare in Japan. Results: Of 422 institutions, 389 responded (92\%) and data were obtained from 379 (90\%). Approximately $90 \%$ of institutions had implemented a distress screening program at some level, and approximately $60 \%$ had just started screening. Among those institutions that screened, $77 \%$ provided individualized triage to specialized services within the institutions, whereas $60 \%$ did not routinely follow-up with patients who had positive screening results. The estimated median percentage of screened patients referred to palliative care teams was $0.4 \%$ in outpatient settings and $6.3 \%$ in inpatient settings. Although $68 \%$ of respondents perceived that screening was useful overall, they also reported difficulties when conducting screening with patients, reporting "no established effective treatment for problems screened" (66\%), "patients complain it is difficult to express their distress using scales" (58\%), and that it was "difficult to manage screened problems because of lack of time" (49\%). Eight perceived barriers to implementing distress screening programs in hospitals were identified; a lack of human resources ranked highest. Conclusions: Implementation of distress screening in designated cancer hospitals in Japan has just begun. Policymakers should acknowledge that screening can be beneficial for patients when it is implemented with appropriate resources and established methods.
\end{abstract}

J Natl Compr Canc Netw 2016;14(9):1098-1104

\section{Background}

In addition to cure of disease and survival, quality of life is an important outcome of cancer treatment. ${ }^{1-3}$ Quality of life is often disrupted by physical, psychological, and social distress, all of which are frequent in patients with cancer. ${ }^{4}$ Although evidence and guidelines suggest that palliative care should be integrated into oncology practice, ${ }^{5-8}$ many patients still have not reaped the benefit of those interventions. ${ }^{9}$ One of the major barriers to effective distress management is inadequate assessment by medical professionals of their patients' symptoms/distress. ${ }^{10}$

From a Division of Psycho-oncology and Palliative Care, Nagoya City

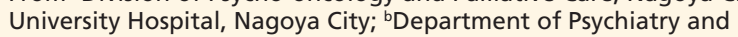
Cognitive-Behavioral Medicine, Nagoya City University Graduate School of Medical Sciences, Nagoya City; 'Department of Palliative Medicine, Kobe University Graduate School of Medicine, Kobe City; ${ }^{\text {dDepartment }}$ of Palliative and Supportive Care, Palliative Care Team, and Seirei Hospice, Seirei Mikatahara General Hospital, Hamamatsu City; and eDepartment of Palliative Medicine, National Cancer Center Hospital East, Kashiwa City, Japan.

Submitted March 2, 2016; accepted for publication May 16, 2016.

The authors have disclosed that they have no financial interests, arrangements, affiliations, or commercial interests with the manufacturers of any products discussed in this article or their competitors. This work was
To overcome such barriers, guidelines, including the NCCN Clinical Practice Guidelines in Oncology for Palliative Care, have recommended routine distress screening, ${ }^{8,11}$ but recent evidence indicates that patients with cancer may not obtain a substantial benefit from screening itself. ${ }^{12-14}$ Screening is considered just one step in a comprehensive screening program that consists of detailed evaluation of patients with positive screening, collaboration with specialty divisions, documentation of screening results, and follow-up of patients with positive screening. ${ }^{15}$ However, few institutions have implemented

supported in part by Grants-in-Aid for Cancer Research from the Ministry of Health, Labour and Welfare, Japan.

Author Contributions: Study conceptualization, methodology, formal analysis, investigation, and writing original draft: Okuyama. Study conceptualization, methodology, formal analysis, investigation, and manuscript composition: Okuyama, Kizawa, and Morita. Study conceptualization, methodology, formal analysis, investigation, manuscript composition, and funding acquisition: Kinoshita and Akechi. Methodology, investigation, and manuscript composition: Uchida, Shimada, and Naito. Correspondence: Tatsuo Akechi, MD, PhD, Department of Psychiatry and Cognitive-Behavioral Medicine, Nagoya City University Graduate School of Medical Sciences, Mizuho-cho, Mizuho-ku, Nagoya City, Aichi 467-8601, Japan. E-mail: takechi@med.nagoya-cu.ac.jp 
such comprehensive screening straightforwardly in busy clinical practice. ${ }^{16}$

In Japan, the Ministry of Health, Labour and Welfare has constructed a system of designated cancer centers to provide quality care throughout the country from 2007 through the Cancer Control Act. Implementation of distress screening in inpatient and outpatient settings has been an essential requirement for designated cancer hospitals since 2015.

The purpose of this study was to investigate the current status of distress screening implementation in Japanese designated cancer hospitals. The hope was that understanding the current status of distress screening would help to clarify the agenda for better distress screening in clinical practice.

\section{Subjects}

The subjects of this study were drawn from all 422 designated regional cancer hospitals in Japan in June 2016. In Japan, establishment of a palliative care team is one of the essential criteria for certification as a designated regional cancer hospital, and mental health professionals are essential for such a team. Japan's Ministry of Health, Labour and Welfare expects that the palliative care team should function as a single point of contact for integrated supportive care services, and that patients with positive screening results should be managed in collaboration with the palliative care team accordingly. Therefore, distress screening primarily falls under the purview of palliative care teams in most of the designated regional hospitals in Japan.

The survey questionnaire was sent to the representative of each institution's palliative care team; we asked that it be forwarded to the person responsible for the screening if the receiver of the survey was not in charge.

We fully explained the purpose of the study and clarified that the respondents had the right to refuse to participate. This study was conducted with the approval of the Institutional Review Board and Ethics Committee of Nagoya City University Graduate School of Medical Sciences, Japan.

\section{Methods}

\section{Procedures}

The mail survey was conducted between August 15 and September 30, 2015. Subjects were asked to com- plete the questionnaire and return it to the study office by mail. If no response was received within 2 weeks of mailing, a reminder was sent (a maximum of 4 reminders were sent). Demographic data in 2014 were also obtained from the Ministry of Health, Labour and Welfare. ${ }^{17}$

This questionnaire was developed based on a review of the relevant literature about distress screening in oncology settings, ${ }^{3,15,18-21}$ and on discussions with oncologists, nurses, palliative care specialists, and psycho-oncologists. Cognitive testing was performed by 4 palliative care physicians or nurses outside the research group. The language of the draft questionnaire was modified in this process to be clearer, more understandable, and easier to answer. The questionnaire comprised 6 parts. Individuals working in institutions where screening had not been implemented were asked to answer the first and sixth parts. All other subjects were asked to respond to all questions. Questions were as follows:

1. Current practice of distress screening. We asked whether subjects had implemented a distress screening program in the outpatient and inpatient settings using a yes/no format for each. If implemented, they were asked the proportion of medical departments in which it had been implemented (<25\%, 26\%-50\%, 51\%-75\%, $76 \%-99 \%$, or $100 \%)$, the timing of screening (periodically at regular intervals, at a predetermined specific point on the disease trajectory, or based on clinical judgment by medical staff), and duration since implementation $(<1$ year, 1-2 years, or $>3$ years).

2. Adherence to the guideline recommendations for a screening program. No unified palliative care screening guidelines were available in Japan. The American Psychosocial Oncology Society and Yale School of Nursing launched the Screening for Psychosocial Distress Program in 2014, in which they clarified the 5 steps of psychosocial distress management: (1) screening, (2) evaluation, (3) referral, (4) follow-up, and (5) documentation and quality improvement. ${ }^{15}$ Subjects reported whether they applied each recommended practice using yes/no responses.

3. Estimated screening results. Subjects reported the estimated number of patients screened, those with positive results, and those referred to a palliative care team according to the 
Okuyama et al

screening results, in both outpatient and inpatient settings, in a previous month. To decrease the respondents' burden, they were permitted to report without formally accessing database or medical records to obtain exact numbers.

4. Perceived usefulness. Subjects reported their perceptions of whether screening improved clinician-patient communication, elicited help for physical problems, elicited help for psychosocial problems, improved the ability to manage patients' problems, and facilitated referral to palliative care specialists, and perceptions of the overall usefulness ${ }^{21}$ using a Likert scale $(1=$ disagree, not useful; 2 = uncertain; 3 = agree, useful).

5. Medical staff-reported difficulties when conducting screening of patients. We measured the degree to which each difficulty was encountered in conducting the screening of patients, ${ }^{21}$ using a Likert scale ranging from 1 to 5 ( $1=$ not at all; 2 $=$ rarely; $3=$ sometimes; $4=$ often; and $5=$ very often). This section included 13 items (Table 1 ).

6. Perceived barriers for implementation of the distress screening program. Finally, we asked subjects to rate whether they perceived 18 barriers for implementation of the distress screening program using a Likert scale $(1=$ disagree; 2 = slightly agree; 3 = agree; Table 2 ).

In addition, we used the following data from the Ministry of Health, Labour and Welfare ${ }^{17}$ : number of beds; annual number of patients with cancer newly registered by the National Cancer Registry in Japan; annual numbers of inpatients with cancer, outpatients with cancer, and inpatients deceased by cancer; and annual number of patients with cancer referred to the palliative care team.

\section{Statistical Analysis}

Descriptive statistics were used to summarize the questionnaire responses. For analysis, we defined sufficient implementation as screening implementation of more than $25 \%$ of the departments in both outpatient and inpatient settings. We applied this definition in order to distinguish institutions with obviously insufficient implementation compared with others. No consensus exists regarding in what proportion of departments screening should be implemented, but it can be easily assumed that the groups of participants who endorsed less than $25 \%$ of departments include few institutions in which screening has been conducted routinely.

\begin{tabular}{|c|c|}
\hline Difficulties & $\begin{array}{c}\text { Proportion of } \\
\text { Institutions Answering } \\
\text { "Sometimes/Often/ } \\
\text { Very Often" } \\
(\%)^{\mathrm{a}}\end{array}$ \\
\hline $\begin{array}{l}\text { No established effective } \\
\text { treatment for the problems } \\
\text { screened }\end{array}$ & 66 \\
\hline $\begin{array}{l}\text { Patients complain that it is } \\
\text { difficult to express their distress } \\
\text { using scales }\end{array}$ & 58 \\
\hline $\begin{array}{l}\text { Difficult to manage screened } \\
\text { problems due to lack of time }\end{array}$ & 49 \\
\hline $\begin{array}{l}\text { Need for lots of time to explain } \\
\text { how to administer screening } \\
\text { questionnaire to patients }\end{array}$ & 47 \\
\hline $\begin{array}{l}\text { Patient was difficult to complete } \\
\text { a screening form for because of } \\
\text { dementia }\end{array}$ & 44 \\
\hline $\begin{array}{l}\text { Patients decline to be referred } \\
\text { to the psychiatric service }\end{array}$ & 40 \\
\hline $\begin{array}{l}\text { Patients decline to be referred } \\
\text { to the palliative care team }\end{array}$ & 36 \\
\hline $\begin{array}{l}\text { Patients decline to be referred } \\
\text { to social work services }\end{array}$ & 34 \\
\hline $\begin{array}{l}\text { Patients are reluctant to fill in a } \\
\text { screening form }\end{array}$ & 33 \\
\hline $\begin{array}{l}\text { Results of the screening form } \\
\text { change too rapidly }\end{array}$ & 30 \\
\hline $\begin{array}{l}\text { Patient was difficult to complete } \\
\text { a screening form for because of } \\
\text { psychiatric disease }\end{array}$ & 28 \\
\hline $\begin{array}{l}\text { Patients do not report the truth } \\
\text { because of a reserved attitude }\end{array}$ & 28 \\
\hline $\begin{array}{l}\text { Patients' anxiety increases } \\
\text { during the screening }\end{array}$ & 12 \\
\hline
\end{tabular}

aResponses were given on a Likert scale ( $1=$ not at all; $2=$ occasionally; $3=$ sometimes; $4=$ often; $5=$ very often).

To obtain the proportion of screened patients referred to the palliative care team, we divided the numbers of patients referred to a palliative care team by numbers of patients screened. To report medical staff-reported difficulties and barriers, we calculated the proportion of institutions scoring from 3 to 5 (sometimes, often, and very often) for difficulties, and those scoring 3 (agree) for barriers, respectively.

Unpaired $t$-tests and chi-square tests were used accordingly to compare the hospital characteristics of participating and nonparticipating institutions, and to explore the factors associated with sufficient imple- 


\begin{tabular}{|c|c|c|c|c|}
\hline Perceptions & $\begin{array}{c}\text { Whole } \\
\text { Sample } \\
(\mathrm{N}=379) \\
\%^{\mathrm{b}}\end{array}$ & $\begin{array}{c}\text { Insufficient } \\
\text { Institutions } \\
(\mathrm{n}=275) \\
\%^{\mathrm{b}}\end{array}$ & $\begin{array}{c}\text { Sufficient } \\
\text { Institutions } \\
(\mathrm{n}=104) \\
\%^{\mathrm{b}}\end{array}$ & $P$ Value \\
\hline Lack of human resources & 54 & 62 & 40 & $<.01$ \\
\hline Difficulty in selection of target patients & 45 & 51 & 33 & $<.01$ \\
\hline Lack of exact knowledge to conduct screening & 29 & 35 & 17 & $<.01$ \\
\hline $\begin{array}{l}\text { No opportunity to discuss the screening system among multiple } \\
\text { professions }\end{array}$ & 24 & 25 & 23 & .69 \\
\hline No availability of IT for screening & 23 & 25 & 21 & .49 \\
\hline $\begin{array}{l}\text { No consensus about how to manage patients with positive screening } \\
\text { results }\end{array}$ & 22 & 26 & 11 & $<.01$ \\
\hline Lack of evidence that proves the effectiveness of distress screening & 21 & 25 & 13 & .02 \\
\hline No routine follow-up system for patients with positive screening results & 21 & 24 & 13 & .02 \\
\hline $\begin{array}{l}\text { No opportunity to share the experience of screening implementation } \\
\text { among institutions }\end{array}$ & 20 & 21 & 22 & .89 \\
\hline $\begin{array}{l}\text { Difficulty in using the same screening tools in outpatient and inpatient } \\
\text { settings }\end{array}$ & 19 & 23 & 10 & $<.01$ \\
\hline No cooperation from physicians & 19 & 22 & 12 & .03 \\
\hline $\begin{array}{l}\text { Difficulty in regulating rules of how to provide screening results to } \\
\text { physicians }\end{array}$ & 18 & 21 & 14 & .14 \\
\hline No person responsible for distress screening & 15 & 20 & 5 & $<.01$ \\
\hline No department for problems screened & 15 & 18 & 7 & $<.01$ \\
\hline No cooperation from nurses & 13 & 15 & 10 & .30 \\
\hline Difficulty in regulating rules of how to record the screening results & 12 & 15 & 5 & .01 \\
\hline No cooperation from hospital heads & 8 & 9 & 5 & .29 \\
\hline Risk of incidents/accidents & 5 & 6 & 2 & .17 \\
\hline
\end{tabular}

asufficient implementation is defined as screening implementation of more than $25 \%$ of departments in both outpatient and inpatient settings. "Proportion of patients that responded "agree."

mentation of the distress screening. A significance level of $P$ less than 0.01 was adopted for all statistical analyses (to correct for multiple comparisons) and $P$ values reported were 2 -tailed. All statistical procedures were performed using SPSS software, version 21.0J, for Macintosh (IBM Corp., Armonk, NY).

\section{Results}

\section{Characteristics of Institutions}

Among 422 institutions, 379 institutions (90\%) provided data. Ten (2\%) refused to participate, and 33 did not respond (92\% response rate). There were no significant differences between institutions participating in this study $(n=379)$ and those not participating $(n=43)$, except that the former tended to report greater annual numbers of referrals to the palliative care team (146 vs 102 per year; $P=.05$ ).

\section{Missing Data on the Questionnaire}

For all questions on the questionnaire, 1,349 responses were missing. Thus, we missed $6.6 \%$ of the total data points.

\section{Current Practice of Distress Screening}

Among 379 institutions, 67\%, 13\%, and 8\% reported that they conducted distress screening programs in both outpatient and inpatient settings, inpatient setting only, and outpatient setting only, respectively. A total of 104 institutions (27\%) met the criterion of sufficient implementation (ie, the proportion of departments in which screening was implemented was more than $25 \%$ in both outpatient and inpatient settings). Distress screening was more likely to be implemented in the inpatient setting (Table 3). Approximately half of the institutions reported that screening had just started ( $<1$ year after implementation). 
Okuyama et al

\section{Adherence to the Recommended Guideline}

The most frequently endorsed practices were "individualized triage to specialized services within the institutions" (77\%), followed by "documentation of screening results" $(75 \%)$. On the other hand, approximately $60 \%$ of institutions did not have routine follow-up systems (Table 4).

\section{Estimated Screening Results}

The reported median number of screenings conducted in a month was 25.0 in outpatient settings and 50.0 in inpatient settings. The percentage of patients who had positive screening results ranged from $2.0 \%$ to $42 \%$, with median of $7.0 \%$ and $15 \%$ in outpatient and inpatient settings, respectively. The median percentage of patients referred to palliative care teams among screened patients was $0.4 \%$ (interquartile range [IQR], 0-6.7) in outpatient settings, and 6.3\% (IQR, 1.2-20.0) in inpatient settings (Table 5).

\section{Perceived Usefulness}

Most of respondents reported screening was beneficial to elicit physical and psychosocial problems (86\% and $83 \%$, respectively). More than half of the respondents perceived that screening improves ability to manage patients' problems $(73 \%)$, facilitates referral to the palliative care specialists (64\%), and improves clinician-patient communication (63\%). Overall, 68\% of respondents perceived that screening was useful.

\section{Medical Staff-Reported Difficulties}

The most frequently endorsed difficulty was "no effective solution for problems screened" (66\%), followed by "patients complain that it is difficult to express their distress using scales" (58\%), "difficult to manage screened problems because of lack of time" (49\%), and "need lots of time to explain how to administer screening questionnaire to patients" (47\%) (Table 1).

\section{Perceived Barriers to Program Implementation}

Eight barriers were reported more frequently in institutions with insufficient screening implementation than in those with sufficient implementation. The top 3 most prevalent barriers in both institution groups were lack of human resources, difficulty in selection of target patients, and lack of exact knowledge to conduct screening. On the other hand, we found no significant differences between these institution groups in number of beds; annual number of patients

\begin{tabular}{|c|c|c|c|c|}
\hline & \multicolumn{2}{|c|}{$\begin{array}{l}\text { Outpatient } \\
\text { Setting }\end{array}$} & \multicolumn{2}{|c|}{$\begin{array}{l}\text { Inpatient } \\
\text { Setting }\end{array}$} \\
\hline & $\mathbf{n}$ & $\%$ & $\mathbf{n}$ & $\%$ \\
\hline \multicolumn{5}{|l|}{ Implementation } \\
\hline Yes & 284 & 75 & 302 & 80 \\
\hline \multirow[t]{2}{*}{ No } & 95 & 25 & 77 & 20 \\
\hline & $n=284$ & $\%$ & $n=302$ & $\%$ \\
\hline \multicolumn{5}{|l|}{ Departments with screening } \\
\hline$<25 \%$ & 164 & 58 & 91 & 30 \\
\hline $26 \%-50 \%$ & 28 & 10 & 29 & 10 \\
\hline $51 \%-75 \%$ & 23 & 8 & 31 & 10 \\
\hline $76 \%-99 \%$ & 32 & 11 & 71 & 24 \\
\hline $100 \%$ & 36 & 13 & 78 & 26 \\
\hline \multicolumn{5}{|l|}{ Timing of screening } \\
\hline Regularly & 49 & 17 & 169 & 56 \\
\hline $\begin{array}{l}\text { Specific points on } \\
\text { the disease trajectory } \\
\text { (eg, at the timing of } \\
\text { breaking bad news) }\end{array}$ & 107 & 38 & 51 & 17 \\
\hline $\begin{array}{l}\text { Based on the clinical } \\
\text { judgment of the } \\
\text { medical staff }\end{array}$ & 55 & 19 & 41 & 14 \\
\hline \multicolumn{5}{|l|}{ Years of implementation } \\
\hline$<1 \mathrm{y}$ & 194 & 68 & 184 & 61 \\
\hline $1-2 y$ & 69 & 24 & 72 & 24 \\
\hline$>3 y$ & 20 & 7 & 39 & 13 \\
\hline
\end{tabular}

with cancer; annual number of inpatients with cancer, outpatients with cancer, and inpatients deceased by cancer; or annual number of patients referred to the palliative care team (data not presented) (Table 2).

\section{Discussion}

This is the first nationwide survey to explore the current status of distress screening in designated cancer hospitals in Japan. The results indicated variable implementation of palliative care screening programs among institutions. Approximately $90 \%$ of designated cancer hospitals have implemented a distress screening program at some level, but only one-fourth of institutions have conducted screening in more than $25 \%$ of departments in both outpatient and inpatient settings, and half of the institutions have just started screening $(<1$ year). These results indicate that many institutions have just started distress screening in the responses to political requirements from the government. 
Distress Screening in Japan

\begin{tabular}{|lc|}
\hline \multicolumn{1}{|c|}{$\begin{array}{c}\text { Table 4. Adherence to Guideline } \\
\text { Recommendations for a Screening } \\
\text { Program (N=333) }\end{array}$} & $\begin{array}{c}\text { Proportion of } \\
\text { Institutions Endorsed } \\
(\%)^{\text {a }}\end{array}$ \\
\hline \multicolumn{1}{|c|}{$\begin{array}{c}\text { Individualized triage to } \\
\text { specialized services within the } \\
\text { institutions }\end{array}$} & 77 \\
\hline $\begin{array}{l}\text { Documentation of screening } \\
\text { results }\end{array}$ & 75 \\
\hline $\begin{array}{l}\text { Evaluation of patients with } \\
\text { positive screening results by } \\
\text { attending physicians or nurses } \\
\text { before referral to specialist team }\end{array}$ & 74 \\
\hline $\begin{array}{l}\text { Routine follow-up of patients } \\
\text { with positive screening results }\end{array}$ & 40 \\
\hline $\begin{array}{l}\text { Administration and analysis of } \\
\text { screening results using computer }\end{array}$ & 25 \\
\hline
\end{tabular}

aSubjects answered these questions using yes/no responses.

According to the systematic review by Mitchell ${ }^{20}$ of distress screening implementation studies, the usefulness of distress screening implementation is controversial; 6 of 14 randomized controlled screening trials have reported added benefits for patientreported outcomes, but only 3 studies have indicated improvement of referral rates. Although differences in healthcare systems could make generalizability of the findings from abroad difficult, no randomized controlled studies have been conducted to examine the usefulness of distress screening implementation in Japan. Recent findings suggest that distress screening should be implemented as a comprehensive program that includes referral, documentation, and follow-up. ${ }^{14,15}$ The present findings indicate that adherence to screening program recommendations was not optimal; therefore, distress screening programs implemented in many Japanese designated cancer hospitals might not contribute sufficiently to the improvement of patients' outcomes.

Our results also indicated that only 1 or fewer of 100 patients screened was eventually referred to the palliative care team in the outpatient setting. There are yet wide variations in referral rates among institutions investigated, and a pioneer work in Japan showed higher referral rates after introduction of a screening project. ${ }^{22}$ There are several possible explanations for this; for example, little time to discuss the results of the screening, especially in the outpatient setting; few resources available to respond to pa-
Table 5. Estimated Screening Results ${ }^{a}$

\begin{tabular}{|lll|} 
& $\begin{array}{l}\text { Outpatients } \\
(\mathrm{N}=\mathbf{2 8 4})\end{array}$ & $\begin{array}{l}\text { Inpatients } \\
(\mathrm{N}=302)\end{array}$ \\
\hline $\begin{array}{l}\text { Number of patients } \\
\text { screened per month }\end{array}$ & 25.0 & 50.0 \\
\hline $\begin{array}{l}\text { Number of patients with } \\
\text { positive results }\end{array}$ & $7.0-70.0$ & $13.0-148.0$ \\
\hline $\begin{array}{l}\text { Number of patients } \\
\text { referred to the palliative }\end{array}$ & $1.0-25.5$ & 15.0 \\
care team according to & $0-2.0$ & $5.0-42.0$ \\
screening results & & 3.0 \\
\hline Referral rate & & $1.0-8.0$ \\
& 0.4 & \\
& $0-6.7$ & 6.3 \\
\hline
\end{tabular}

aNumbers in each cell indicate median number of patients, interquartile range.

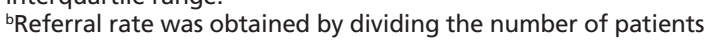
referred to a palliative care team by the number of patients screened.

tients' problems (some palliative care teams may not provide outpatient services); and failure to select appropriate screening populations. Implementation of the triage and referral algorithms in clinical practice may facilitate referral to the supportive care service and therefore contribute to lessening patients' distress. ${ }^{12}$ However, the rate of referral to palliative care teams should be reserved as an alternative indicator of the effectiveness of palliative care screening.

When conducting distress screening of patients, medical staff reported that 10 of the 13 difficulties were experienced frequently, indicating that distress screening was burdensome for frontline staff. Approximately half of respondents reported difficulty in managing screened problems because of lack of time. This problem may have a large influence on the effectiveness of screening.

The most frequently reported barriers to implement distress screening programs in hospitals were lack of human resources, exact knowledge regarding effective screening, and skills to implement screening in clinical practice. Sufficient staff and training are crucial to implement distress screening. ${ }^{20}$ Based on a literature review, Carlson et $\mathrm{a}^{19}$ recommended appropriate staff training for successful program implementation, and our results are consistent with this recommendation. ${ }^{19}$ We believe that the assignment of managers to comprehensive screening programs is desirable, because these individuals could apply recommended screening practices to busy clinical practices. Several studies indicated the possibility of screening large numbers of patients in pragmatic settings. ${ }^{23,24} \mathrm{Ad}-$ ditionally, we detected several institutions in which suc- 
Okuyama et al

cessful screening implementation has been achieved. Learning from such successful screening models must be beneficial for other institutions to acquire knowledge and skills for feasible and effective screening.

This study has several strengths. First, the response rate was sufficient. Second, the results of the mailed survey were combined with demographic data from a national database of regional cancer hospitals in Japan. Several study limitations should also be acknowledged. The psychometric properties of the questionnaire were not examined. The questionnaire results reflected subjective views by healthcare professionals responsible for distress screening in an institution. No audits or outcomes reported by patients or their families were included. In addition, we did not investigate what resources other than palliative care teams were used to respond to the problem screened.

\section{Conclusions}

The distress screening programs in designated cancer hospitals in Japan have just begun. We believe that imposing requirements for implementing distress screening programs in designated cancer hospitals in Japan is a win-win situation for integrating palliative care into oncology practice in Japan. However, this goal will not be realized if screening is not implemented in a meaningful way that is less burdensome to frontline staff. Policymakers should acknowledge that screening can be beneficial for patients when implemented with appropriate resources and established methods.

In the next step of this study, we aim to extend the present findings by developing a model program that fits the Japanese medical system, and to investigate its effectiveness based on patient-reported outcomes in randomized controlled trials.

\section{Acknowledgements}

The authors gratefully acknowledge the support of the study participants.

\section{References}

1. Wedding U, Pientka L, Hoffken K. Quality-of-life in elderly patients with cancer: a short review. Eur J Cancer 2007;43:2203-2210.

2. Zikos E, Ghislain I, Coens C, et al. Health-related quality of life in smallcell lung cancer: a systematic review on reporting of methods and clinical issues in randomised controlled trials. Lancet Oncol 2014;15:e78-89.
3. Peppercorn JM, Smith TJ, Helft PR, et al. American Society of Clinical Oncology statement: toward individualized care for patients with advanced cancer. J Clin Oncol 2011;29:755-760.

4. Avis NE, Crawford S, Manuel J. Quality of life among younger women with breast cancer. J Clin Oncol 2005;23:3322-3330.

5. Faller H, Schuler M, Richard M, et al. Effects of psycho-oncologic interventions on emotional distress and quality of life in adult patients with cancer: systematic review and meta-analysis. J Clin Oncol 2013;31:782793.

6. Temel JS, Greer JA, Muzikansky A, et al. Early palliative care for patients with metastatic non-small-cell lung cancer. N Engl J Med 2010;363:733742 .

7. Smith TJ, Temin S, Alesi ER, et al. American Society of Clinical Oncology provisional clinical opinion: the integration of palliative care into standard oncology care. J Clin Oncol 2012;30:880-887.

8. Levy MH, Smith T, Alvarez-Perez A, et al. Palliative care, Version 1.2014 Featured updates to the NCCN Guidelines. J Natl Compr Canc Netw 2014;12:1379-1388.

9. Forsythe LP, Kent EE, Weaver KE, et al. Receipt of psychosocial care among cancer survivors in the United States. J Clin Oncol 2013;31:1961-1969.

10. Cleeland CS, Gonin R, Hatfield AK, et al. Pain and its treatment in outpatients with metastatic cancer. N Engl J Med 1994;330:592-596.

11. National Institute for Clinical Excellence. Improving Supportive and Palliative Care for Adults with Cancer. Available at: https://www.nice.org. uk/guidance/csg4/resources/improving-supportive-and-palliative-care-foradults-with-cancer-773375005. Accessed December 1, 2015.

12. Carlson LE, Groff SL, Maciejewski O, Bultz BD. Screening for distress in lung and breast cancer outpatients: a randomized controlled trial. J Clin Oncol 2010;28:4884-4891.

13. Hollingworth W, Metcalfe C, Mancero S, et al. Are needs assessments cost effective in reducing distress among patients with cancer? A randomized controlled trial using the distress thermometer and problem list. J Clin Oncol 2013;31:3631-3638.

14. Pirl WF, Fann JR, Greer JA, et al. Recommendations for the implementation of distress screening programs in cancer centers: report from the American Psychosocial Oncology Society (APOS), Association of Oncology Social Work (AOSW), and Oncology Nursing Society (ONS) joint task force. Cancer 2014;120:2946-2954.

15. Lazenby M, Tan $H$, Pasacreta N, et al. The five steps of comprehensive psychosocial distress screening. Curr Oncol Rep 2015;17:447.

16. Albizu-Rivera A, Portman DG, Thirlwell S, et al. Implementation of NCCN Palliative Care Guidelines by member institutions. Support Care Cancer 2016;24:929-932.

17. Ministry of Health, Labour and Wealth, Japan. Status of designated regional cancer treatment hospitals in 2014 (in Japanese). http://www. mhlw.go.jp/stf/seisakunitsuite/bunya/kenkou_iryou/kenkou/gan/gan_ byoin.html. Accessed February 19, 2016.

18. Bultz BD, Waller A, Cullum J, et al. Implementing routine screening for distress, the sixth vital sign, for patients with head and neck and neurologic cancers. J Natl Compr Canc Netw 2013;11:1249-1261.

19. Carlson LE, Waller A, Mitchell AJ. Screening for distress and unmet needs in patients with cancer: review and recommendations. J Clin Oncol 2012;30:1160-1177.

20. Mitchell AJ. Screening for cancer-related distress: when is implementation successful and when is it unsuccessful? Acta Oncologica 2013;52:216-224.

21. Mitchell AJ, Lord $K$, Slattery J, et al. How feasible is implementation of distress screening by cancer clinicians in routine clinical care? Cancer 2012;118:6260-6269.

22. Morita T, Fujimoto K, Namba M, et al. Palliative care needs of cancer outpatients receiving chemotherapy: an audit of a clinical screening project. Support Care Cancer 2008;16:101-107.

23. Shimizu K, Ishibashi Y, Umezawa S, et al. Feasibility and usefulness of the 'distress screening program in ambulatory care' in clinical oncology practice. Psychooncology 2010;19:718-725.

24. Watson L, Groff S, Tamagawa R, et al. Evaluating the impact of provincial implementation of screening for distress on quality of life, symptom reports, and psychosocial well-being in patients with cancer. J Natl Compr Canc Netw 2016;14:164-172. 